\title{
Experimental study on bending bearing capacity of bamboo- reinforced
}

\section{concrete plate}

\author{
Mingqiao Zhu ${ }^{1, a}$, Yong Long ${ }^{1, b^{*}}$ Qiao Jiang ${ }^{1, c}$, Jie Li $^{1, c}$ \\ Hunan University of Science and Technology, China,Xiangtan \\ a1531290279@qq.com, b814980506@qq.com, c824743550@qq.com
}

\begin{abstract}
Keywords: bamboo; bamboo reinforcement;Plate; the deflection;
Abstract: as the global resources is increasingly scarce and the environment is worse, people put forward the higher request for building materials and environmental protection. And bamboo is economy ,renewable and environmental protection. Apply bamboo instead of steel to concrete plate, increase the hollow rate of the plate and achieve the goal of reducing weight. The three different reinforcement ratio of bamboo stiffened plates under uniformly distributed load are carried on bending test to study the mechanical performance of bamboo reinforced concrete plate.Through the experiment phenomenon, deflection, strain change rule of the component and crack development process, it is conclued that when plate damage, its midspan deflection can reach above $l 0 / 25$ and its ductility is good; the bending process of bamboo reinforcement plate present two stage characteristics, namely the elastic stage before cracking and crack work until failure;combining with the test data of deflection, strain and crack, propose the construction measures and suggestions about the design of bamboo reinforcement concrete plate.
\end{abstract}

\section{THE INTRODUCTION}

Bamboo is economy, renewable and environmental protection. Apply bamboo instead of steel to concrete plate, which not only reduce plate weigh and cost, and also have obvious effection on the heat insulation, sound insulation, heat preservation. Bamboo reinforced concrete plate [1] have the effect of alternative steel through the moso bamboo distribute on the bottom of the plate, at the same time, bamboo shoot as a distributing reinforcement distribute uniformly in bamboo upper and lower section and tangency,which strengthen the integrity of plate. The tube body of moso bamboo is hollow, which meets the hollow ratio of plate, not only reduce plate weigh and also improve heat insulation, sound insulation effection obviously, not only built-in bamboo cavity to make a whole plate of sound insulation and heat insulation effect is improved obviously. At present, the research mainly focuses on the bamboo shoot instead of steel that is used in the concrete plate[2-11] and it has made many achievements. But theory and experimental study on the whole moso bamboo instead of steel to realize the stress of the bamboo- reinforced concrete plate is less. In order to make the bamboo- reinforced concrete plate is applied, it is necessary to lucubrate its mechanical behavior to provide theoretical foundation. With a global shortage of resources and seriously environmental pollution, stress performance research on the moso bamboo instead of steel in concrete plate has important theoretical and realistic significance.

\section{THE GENERAL SITUATION OF THE TEST}

\section{Specimen design}

In the test, three bamboo- reinforced concrete plates are designed, whose bamboo numbers are four, $f$ 
ive,six respectively. The longth of plates is $3000 \mathrm{~mm}$, the width is $500 \mathrm{~mm}$ and the thickness is $100 \mathrm{~m}$ $\mathrm{m}$. The diameter of the bamboo is in between $38 \mathrm{~mm}$ and $42 \mathrm{~mm}$, because of the smooth surface of the bamboo, two floors bamboo should be arranged as distribution bars and the Spacing of bamboo is $100 \mathrm{~mm}$; Adopting double wiring connect bamboo and Passing through two or three end of bamboo to deal with anchor end of bamboo. In order to increase the bamboo and concrete bonding area, cuting $1 / 3$ to $1 / 2$ - bamboo section in one or two bamboo (nd) range(Adopt $8 \mathrm{~d}$ in test). Concrete and slipping of the bamboo section does not take place when Breaking the concrete slab after the completion of the test. The result shows that the effect of slip resistance measures is very good. Bamboo reinforced concrete cover thickness is $25 \mathrm{~mm}$, Implementing all the alternative bar for ordinary reinforced concrete plate. As shown Specimen size and reinforcement in figure 1, 2.

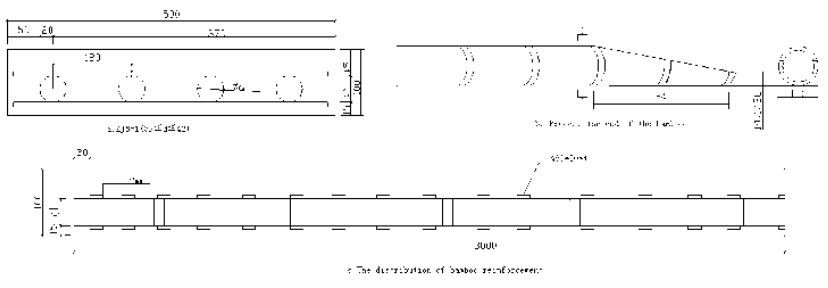

Fig 1.Dimensions and reinforcement details ZJB-1

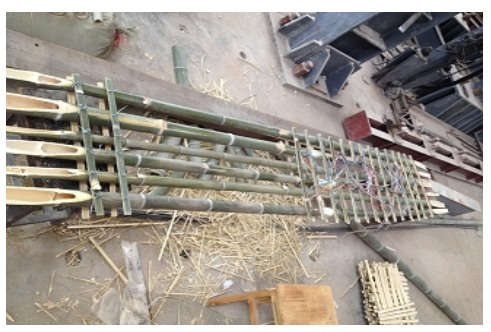

Fig.2 Binding bamboo reinforcement on the of site

Material performance indicators: concrete strength design level are C25, The compressive strength standard values With $95 \%$ reliability is $f_{c u . k}=24.32 \mathrm{Mpa}$. The value of modulus of elasticity of concrete is $2.8 \times 10^{4} \mathrm{Mpa}$, The average moisture content of bamboo is $9.18 \%$, The value of modulus of elasticity of bamboo $^{[5]}$ is (12-20) Gpa.

Table 1 Parameters of specimens

\begin{tabular}{|c|c|c|c|c|c|c|c|}
\hline \multirow{2}{*}{$\begin{array}{c}\text { specimen } \\
\text { Serial } \\
\text { number }\end{array}$} & \multirow{2}{*}{$\begin{array}{c}\text { The } \\
\text { strength of } \\
\text { concrete } \\
\text { Design } \\
\text { level }\end{array}$} & \multicolumn{2}{|c|}{ Section size } & \multirow{2}{*}{$\begin{array}{l}\text { The number of } \\
\text { bamboo } \\
\text { reinforcement } \\
/ \mathrm{n}\end{array}$} & \multirow{2}{*}{$\begin{array}{l}\text { range of } \\
\text { bamboo } \\
\text { diameter } \\
/(\mathrm{mm})\end{array}$} & \multirow{2}{*}{$\begin{array}{l}\text { The cross } \\
\text { section of the } \\
\text { reinforcement } \\
\text { ratio } \rho /(\%)\end{array}$} & \multirow{2}{*}{$\begin{array}{c}\text { Hollow } \\
\text { Ratio } \\
/(\%)\end{array}$} \\
\hline & & $\begin{array}{c}\mathrm{b} / \\
(\mathrm{mm})\end{array}$ & $\begin{array}{c}\mathrm{h} / \\
(\mathrm{mm})\end{array}$ & & & & \\
\hline ZJB-1 & $\mathrm{C} 25$ & 509 & 105 & 4 & $40-43$ & 7.68 & 5.87 \\
\hline ZJB-2 & $\mathrm{C} 25$ & 510 & 106 & 5 & $39-42$ & 8.92 & 6.90 \\
\hline ZJB-3 & $\mathrm{C} 25$ & 507 & 115 & 6 & $39-42$ & 12.1 & 7.41 \\
\hline
\end{tabular}

In the table ,Cross section of the reinforcement ratio formula is $\rho=\frac{z_{S}}{b h_{0}}$.Among them, Zs represent the cross sectional area of the longitudinal stress bamboo reinforced $h_{0}$ represent the effective

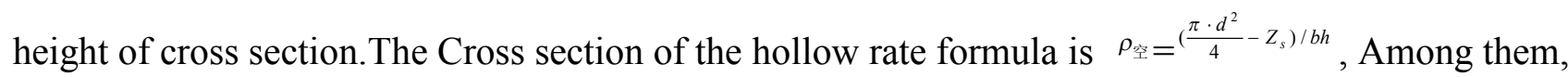
$\mathrm{d}$ represent average diameter of bamboo and other parameters are same as above.

1.2 The arrangement of loading scheme and the measuring point

Loading plan and Arrangement of measuring points. the way of Loading is the hierarchical load farmar with sandbags(as shown in figure 3), At first, adopting A weight loading from the central to on both ends with symmetry. 


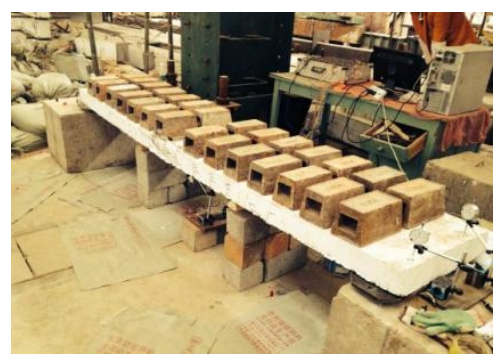

Fig.3 Loading test site

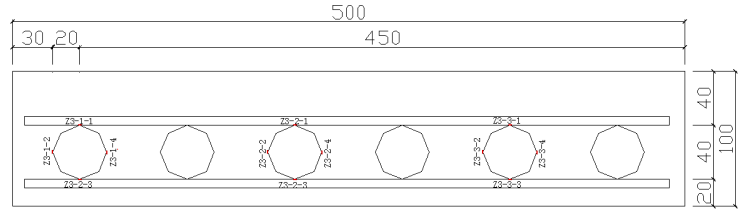

Fig.4 Position of bamboo gages in reinforcing bars

\section{Decorate a strain gauge}

The concrete strain gauge is decorated in the bamboo surface。In bamboo cross section, Arrangement of strain gauge is in the up, down, left and right four direction (As shown in figure 4) Decorate evenly spaced concrete strain gauge to control panel stress concrete strain in the process of change in the longitudinal cross section of plate.

\section{Deflection measurement}

In order to measure the deflection of bamboo concrete under All levels of load. The hollow bamboo concrete slab belongs bearing component. To ensure compliance with design and calculation of the basic rules USing the fixed support to Trial end, at the other end, USing roll hinge support. Fit with a dial indicator in the span and bearing of the plate(as shown in figure 5).

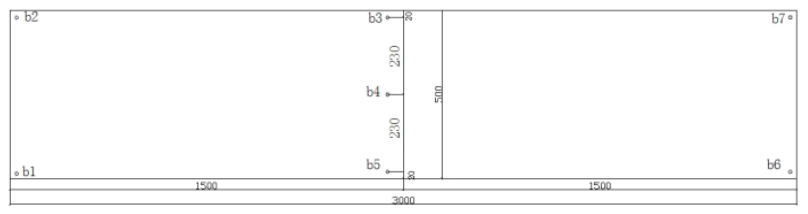

Fig.5 Position of measuring points

\section{THE EXPERIMENTAL PHENOMENON AND RESULTS}

\section{Bending moment - deflection (M- $\triangle$ ) curve (no calculating the self-weight)}

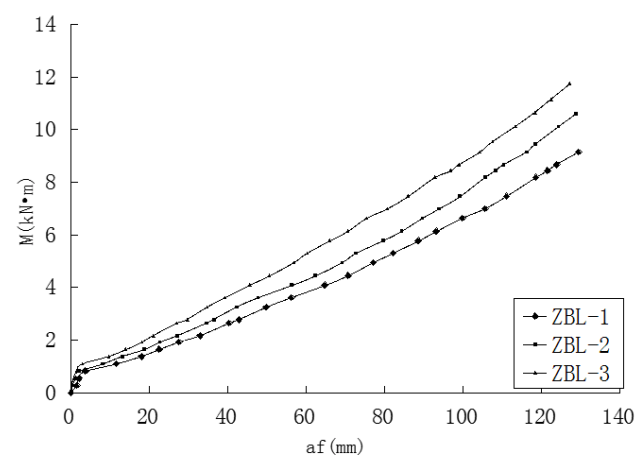

Fig.6 Bending moment- deflection change curve

Deflection is one of the important factors in controlling the whole bending process of bamboo reinforcement plate. Analysing the bending deflection curve as shown in figure 6 , shows that plate is in the elastic work stage before cracking ; concrete in drawed area exit work after cracking, flexural stiffness of section decrease, deflection is growing rapidly, the curve turn obviously, the plate work with crack until the destruction, the force characteristic of plate present two stages.

Analysing the slope of bending moment - deflection curve,shows that before the concrete cracking, the curve slope of three plates change similarily before cracking. With the increase of 
bamboo reinforcement ratio,section material properties are changed to some extent, which cause cracking load is different;After cracking,midspan deflection growth of the plates are different. With the increase of bamboo reinforcement ratio, integral rigidity of the plate increases, midspan deflection of plate decreases obviously and bending resistance of cross section is improved. When the plate deflection reaches $\mathrm{f} \geqslant l_{0} / 50$, at this time, the strain and crack of bamboo- reinforced concrete plate are still in the normal and the bamboo reinforcement plate is in a good ductility compared with common reinforced concrete plate; bamboo strain and the plate deflection continues to increase with continuing to load. When the deflection exceeds (130-140) $\mathrm{mm}\left(l_{0} / 23-l_{0} / 22\right)$, at this point, the deformation of bamboo reinforcement plate is large, the cracks have also reached the sign of failure and the plate can't meet the work demand until destruction.

Above all, 1) with the bamboo number change of the plate, the effection on the value of cracking load is little ;2)The deflection of bamboo reinforced concrete plate can reach above $\left(l_{0} / 23\right.$ $-l_{0} / 22$ ), which shows the ductility is very good .3) The deflection change of bamboo- reinforced concrete plate is different from ordinary reinforced concrete, the whole change process of present two phases and there is no stable period and decline period.

\section{The bending moment and strain}

In combination with the bamboo bending strain graph (7) shows that as the bending moment increase gradually, average strain of bamboo has little change and present linear change before concrete cracking, curve appear obvious turning point after concrete cracking, the strain change is larger and present nonlinear change,the increase amplitude is significantly greater than that before cracking.

Loading before destruction, and the average strain in bamboo midspan of three plates reached $5126^{\mu \varepsilon} 、 5199^{\mu \varepsilon} 、 5101^{\mu \varepsilon}$ respectively, at the same time, concrete strain reach corresponding to $2811^{\mu \varepsilon} 、 2892^{\mu \varepsilon} 、 2801^{\mu \varepsilon}$;Respectively bamboo strain (bamboo is divided into the upper,middle and lower three parts according to strain layout), concrete strain are put in a calculation diagram of single steel rectangle cross section, the result shows that strain change of the parts of cross section in bamboo- reinforced concrete plate meet the calculation diagram in the progress of stress, which shows stress strain relation of the concrete and the bamboo accord with flat section assumption in the plate bending process .

Before the plate destroying, the strain change curve of whole moso bamboo present two phase characteristics; Analyse local stress and strain characteristics of the single bamboo in plate combined with single plate bamboo bending moment strain curve, which indicates that bambooreinforced concrete plate in the process of bending until destruction, the bamboo near the bottom part bear main tensile stress, the two sides bear less and the stress is relatively uniform, the top bear the minimum stress.

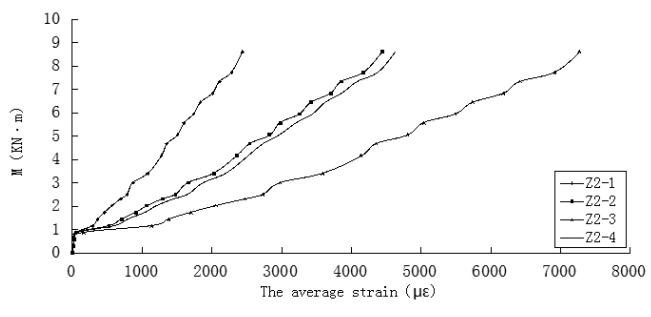

Fig. 7 The bending moment and strain curve of bamboo 


\section{Cracks distribution \\ cracks distribution before experiment}

During the maintenance of specimens, long crack occurred along plate direction across the plate surface and the three boards longitudinal cracks have two common characteristics as follows:1) Crack development to (260-320) $\mathrm{mm}$ far from the two short side failed to continue. However, end of the bamboo cut $1 / 3$ to $1 / 2$ - bamboo section equably in the range of $1-2$ slub ( $8 \mathrm{~d}$ ) by getting through 2-3 end bamboo as following graph; 2) Longitudinal cracks' distance from the long side edges is close to the top bamboo's distance from the edge. This is because bamboo in plate is close to elliptical or circular, and bamboo in the upper part of the concrete is similar to the shape of arch, which can make uneven deformation on the surrounding medium, then cracks are produced. Whereas, "hoop" produced by bamboo piece's transverse distribution of the up and down can inhibit cracks very well. This is why bamboo sticks bamboo reinforced concrete plate occur long longitudinal cracks easily on both sides of the plate during curing.

Early cracks' reasons may be as follows:1) Generally, irregular contraction crack caused by the lack of maintenance and poor stability of concrete during construction. 2) Bamboo belongs to natural renewable green plants, which has strong water imbibition. The moisture content of natural bamboo can reach more than $50 \%$, and the average moisture content of materials is $9.2 \%$ before the test through the experiment measured. Therefore, cracks on the plate are caused by untreated bibulous bamboo. 3) Temperature causes cracks and so on.

\section{crack expansion in the test process}

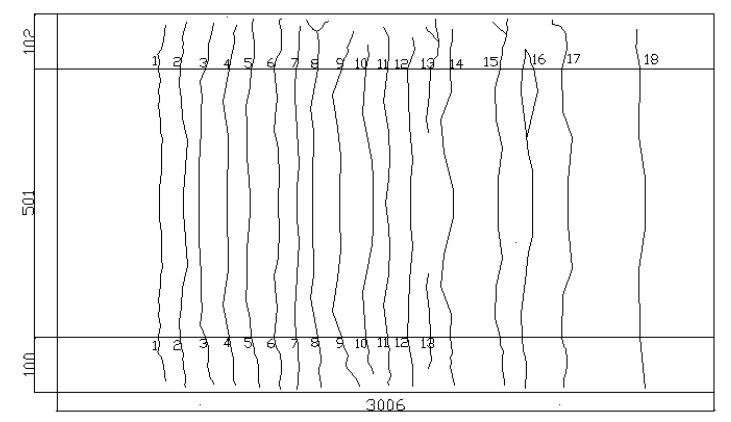

Fig. 8 crack expansion of plate bottom

According to the test observation and test specimen crack expansion in figure 7, the distribution, spacing and width of specimen crack has the following characteristics: 1) Break the plate to observe crack distribution and indicates that the crack mainly distribute between the distributing reinforcement 2) cracks distribution and expansion are related to the reinforcement ratio of the specimens. With the reinforcement ratio increases, the crack spacing and width is bigger .For example:ZBL-1/ZBL-2 once appear cracks, the maximum crack width reaches about $0.1 \mathrm{~mm}$; When it reaches ultimate load, the average crack width is $123.8 \mathrm{~mm}$ and $130.72 \mathrm{~mm}$ respectively. The reinforcement ratio is bigger, the cracks are relatively wide and sparse.For example: $\mathrm{ZBL}-3$ is up to $0.3 \mathrm{~mm}$ as cracks appeared, the crack spacing is up to $165 \mathrm{~mm}$ under the limit load.

\section{CONCLUSIONS AND RECOMMENDATIONS}

By studying stress performance test of 3 piece of Bamboo reinforcement concrete slab, With analysis and comparison test data of the results, can draw the following conclusion:

1) Bmboo reinforced concrete board present two-stage damage characteristic plate before the board would damage,from the initial load to the destruction, which experienced before the list and the fracture work; with the whole process of the plate bending, the relationship of concrete and 
bamboo stress-strain process accord with flat section assumption; because the deflection can reach above $l_{0} / 25$, Three pieces of plate show ductility from bending to destroyed; .

2)After breaking the plates, it is found that there is no relative slip between the bamboo and concr ete and the anchor end is surrounded by concrete like "fist", which illustrates the slip resistant meas ures of bamboo- reinforced concrete plate is effective. It is suggested that two floors bamboo should be arranged as distribution bars and the Spacing of bamboo is $100 \mathrm{~mm}$; it is recommended that the end of treatment bamboo should be anchored by opening the ends of bamboo with 2-3 and 1-2 in the bamboo (8d) range and slashing the 1/2-1/ 3 bamboo sectional.

3) With the reinforcement ratio of plate increasing, the greater the crack spacing, the wider the crack width among the process of bending plate. The effect of bonding between bamboo and concrete is not well without any handling of poor bamboo.Taking into account bamboo itself is waterproof anti-corrosion requirements, It is important to consider bond issue between bamboo and concrete. so it is suggested that,in future studies, we can handle the surface of bamboo by Choosing a functional glue with waterproof and anticorrosive;

\section{ACKNOWLEDGMENT}

This paper is funded by the national natural science fund project and the graduate student of hunan university of science and technology innovation fund project. The corresponding project number of this fund is 51378202 ,and the other is S140011.

\section{REFERENCES:}

[1] Mingqiao zhu, Long Yong, Chenkun Liang. Bamboo reinforced slab Of cast-in-place concrete: China, ZL201420428872.3 [P]. 2014

[2] Yunfang Yang, Zhikun Liu. Mao bamboo tensile elastic modulus and tensile strength. Journal of Zhejiang Forestry College, 1996, 13 (1) : $21 \sim 27$

[3] Yunfang Yang. Bamboo as a concrete floor reinforced material suitability study [J]. Journal of FuZhou, FuJian Forestry College, 1996 (2) : $105 \sim 108$

[4] Yi li Wu, Jinsong Zhu etc. Bamboo reinforced concrete floor slab test study [J]. Journal of Chemical Industry Production Technology, 1998 (3) : 62

[5] Yili Wu, Aiming Jiang etc. Bamboo reinforced concrete floor check [J]. Engineering Mechanics (supplement), 2001 (38) : $383 \sim 388$

[6] Lu Chen .Bamboo bar - ceramsite concrete bonding properties and the performance ofcomposite wall panel bending test and theory analysis [D]. Hunan University, 2012.

[7] Qian Zhou. Bamboo reinforced concrete hollow slab stress performance research and analysis [D]. Changsha, Hunan University, 2012.

[8] Songxian Xie .Bamboo reinforced concrete floor slab structure performance test and evaluation [J]. Journal of Building Structure Design, 2010, 11:39-42

[9] Wenfu Zhang. Applications and research progress of round bamboo [J]. Journal of Bamboo Research Proceedings, 2011, 30 (2) : 1-4

[10] GB 50010-2010 concrete structure design code [S].

[11]Zhenhai Guo. [12] the principle of reinforced concrete [M]. Beijing: Qinghua University Press, 1999. 